\title{
Comparative use of field and laboratory mesocosms for in-stream nitrate uptake measurement
}

\author{
T. Turlan 1 , F. Birgand ${ }^{2 *}$, P. Marmonier ${ }^{3}$
}

\author{
${ }^{1}$ Le Village, F-31110 Saint-Paul d'Oueil, France \\ ${ }^{2}$ Cemagref, UR Hydrosystèmes et Bioprocédés, Parc de Tourvoie, BP 44, 92163 Antony Cedex, France \\ ${ }^{3}$ ECOBIO-UMR CNRS n ${ }^{\circ}$ 6553, Ecosystèmes, Biodiversité, Evolution, Université de Rennes 1, Campus Beaulieu, Bât. 14A, Avenue du \\ Général Leclerc, F-35042 Rennes Cedex, France.
}

Recent publications suggest that in large watersheds a large proportion (20 to $70 \%$ ) of the net nitrogen input to the aquatic environment may be removed during water's downstream path towards the outlet. In small watersheds there are few to no evaluations of the importance of in-stream processes in the overall nitrogen budget due in part to the lack of simple and robust methods for measuring in-stream nitrate uptake. We propose a comparative study for laboratory and field measurements on open mesocosms, $30 \mathrm{~cm}$ in diameter. Nitrate uptake was evaluated from the kinetics of disappearance of nitrate in water overlying undisturbed sediment cores, both in the laboratory and in-situ. Using both laboratory and in-situ mesocosms was an effort to determine whether the methods were comparable and applicable on a routine basis. Nitrate disappearance kinetics in the laboratory yielded expected results, which are that nitrate uptake rates are linearly correlated to nitrate concentration in the water column. In such conditions, our results show that the potential for nitrate uptake in streams can be calculated from the mass transfer coefficient. Our comparative study shows that incubations conducted in the laboratory intrinsically limit hyporheic exchanges, associated with small water level fluctuations, which may in fact prevail in the field as the in-situ incubations have shown. In-situ experiments yielded unexpected results, such as the succession of disappearance and gain of nitrate in the mesocosms through time. This was attributed to hyporheic exchanges, both natural and artificially induced by the design of the mesocosms. Both methods should be considered for future nitrate uptake studies as they yield complementary results, provided that some simple changes are made in the design of in-situ mesocosms.

Keywords In-stream processes, nitrate uptake, mesocosm, method, mass transfer coefficient

\section{Introduction}

Most developed countries are experiencing serious environmental problems around the world. Increasing eutrophication of coastal waters in particular (e.g. Hallegraeff 1993) has been linked in part to the general increase of riverine nutrients (particularly nitrogen) and sediment loads to the estuarine systems (e.g. Justić et al. 1995, Valiela et al. 1992, Officer et al. 1984, Larsson et al. 1985, Rosenberg 1985, Baden et al. 1990, Burkholder et al. 1993). Reducing nitrogen load to receiving water bodies has become a priority in the western world (e.g. Directive 91/676/EEC, Clean Waters Act Section 319, 1987). Concurrently, agriculture has been recognized in many regions of the world as the single largest source of nitrogen emissions to aquatic environments, and as a result, vast programs of nutrient reduction at the field edge have been proposed and implemented. However, reducing coastal eutrophication

\footnotetext{
* Corresponding author : E-mail : francois.birgand@ cemagref.fr
}

or nitrate concentration in drinking water supply, implies nutrient management, not only at the field scale, but also at the watershed scale. The key to nutrient management at this scale is the understanding and quantification of the fate of nutrients at the field scale, and after they enter the aquatic environment. Recent publications suggest that in large watersheds (several $10,000 \mathrm{~s}$ of $\mathrm{km}^{2}$ ) a large proportion (20 to 70\%) of the net nitrogen input to the aquatic environment may be removed during water's downstream path towards the outlet (e.g. Howarth et al. 1996, Alexander et al. 2000). In small watersheds (several 100s of $\mathrm{km}^{2}$ ), there are few to no evaluations of the importance of in-stream processes in the overall nitrogen budget as the global mass balance approach used by the previous authors may not be easily implemented. While Alexander et al. (2000) suggest that in-stream nitrogen retention is linked to the size of the stream section, there is still much to learn in small watersheds, however, about which parameters, other than the hydraulic ones, may force a particular reach to retain more nitrogen than another one. 
Methods have been proposed to quantify in-stream nitrogen retention, usually classified into laboratory, in-situ and whole-reach methods (reviewed by Birgand et al. in press). The mesocosm method consists in monitoring over time the decrease of nitrate concentration in water overlying sediment, both being physically bounded by what may be described as a mesocosm. Mesocosm studies can be conducted either in the laboratory or in-situ. Most reports relate experiments in wetlands (e.g. Ingersoll \& Baker 1998, Burchell 2003) in drained soil (Rückauf et al. 2004) or in soil with vegetation influence (Yang et al. 2001). More recently, several authors have used them on sediment (e.g. Appelboom 2004; Stief et al. 2003). Using the mesocosm method on the same sediment material both in the laboratory and in-situ is of particular interest because, while in-situ measurements are difficult to conduct in the field, laboratory ones can be conducted in controlled conditions and at predicted periods of time. This research thus investigates whether both methods can lead to similar results and whether they could be recommended when investigating nitrogen retention in small streams.

\section{The mesocosms}

Using in-situ mesocosms provides great advantages as local physical and chemical parameters correspond to field conditions. On the other hand, the laboratory mesocosm system allows studying sediment nitrate uptake at known environmental conditions. In both cases, great care must be taken to disturb the sediment in place the least. To minimize disturbance before incubation in the field, and because an entire mesocosm could not be left permanently in streams, a permanent frame was left in place throughout the year. The permanent frame was made of a driven-in PVC sleeve associated to a PVC base plate (Fig. 1A). To drive the $30-\mathrm{cm}$ in diameter sleeve, the PVC part was gently pushed down making sure the sediment entrapped would be disturbed to a minimum. Downward pressure was not sufficient, however, to drive the sleeve deep enough into the sediment, as gravel or coarse sand would get in the way. Sediment around and outside the PVC sleeve was thus excavated down to the base of the sleeve to let the excess sediment below the sleeve lip move out of the way. The PVC sleeve was driven approximately $20 \mathrm{~cm}$ into the sediment while leaving around $5 \mathrm{~cm}$ protruding above the sediment surface (Fig.1A). The disturbed sediment around the sleeve was then pushed back into place. This operation was performed in summer base flow when flow had either ceased or was minimal. The top sediment in the frame was thus representative of sediment in the vicinity and underwent the same environmental conditions throughout the year.

A $31.6 \mathrm{~cm}$ diameter hole was made in the PVC base plate $(50 \times 50 \times 1 \mathrm{~cm})$, which was then slid down the sleeve and anchored on the sediment using construction iron (Fig.1B). Three replicate permanent frames were installed and left in place for each study site. To perform nitrate uptake measurement assays, the volume of water above the sediment was momentarily isolated using a top sleeve that was slid onto the permanent frame (Fig. 1B). The top sleeve was bolted in place using screws attached to the base plate and to legs welded at the base of the sleeve (Fig. 1B). To prevent exchange between mesocosm and stream waters, a foam neoprene O-ring was used between the three parts (Fig. 1B). The resulting mesocosm thus isolated stream water where both sediment-water and atmosphere-water exchanges could prevail.

For comparison purposes, undisturbed sediments were recovered for laboratory mesocosms near the site where the in-situ experiments were conducted. Mesocosm recovery was performed in a very similar way to that already described for the in-situ mesocosms. A 40 $\mathrm{cm}$ long and $30 \mathrm{~cm}$ in diameter PVC sleeve was driven in the sediment in the manner described earlier down to $25 \mathrm{~cm}$ in depth. Sediment around the sleeve was then excavated so that a flat plate could be placed underneath. The whole mesocosm was then carefully extracted and brought back to the laboratory. The sleeve was then welded to the plate to prevent leaks during nitrate uptake experiments.

\section{Study site}

The study was carried out on sediments of drainage ditches of the Cétrais research watershed located in Western France. This watershed was monitored between 1997 and 2003 for agricultural diffuse pollution. Land use in the watershed $\left(35.1 \mathrm{~km}^{2}\right)$ is mainly divided into grain production (25\% of wheat, $18 \%$ of maize, $3 \%$ of sunflower) and permanent grass (49\% of the area). Crops sustain an important dairy production $(260,000$ liter/day) on the watershed.

The land is naturally poorly drained as soil hydraulic conductivities are rather low and as the flatness of the area provides few topographic outlets. Nonetheless, the drainage density is rather elevated $\left(1.125 \mathrm{~km} / \mathrm{km}^{2}\right.$; Delajon 1998), corresponding to the excavation of ditches and canals that carry water from artificial drainage. As drainage functions only during part of the year, the majority of the ditches function on an intermittent basis and may remain dry during part of the 

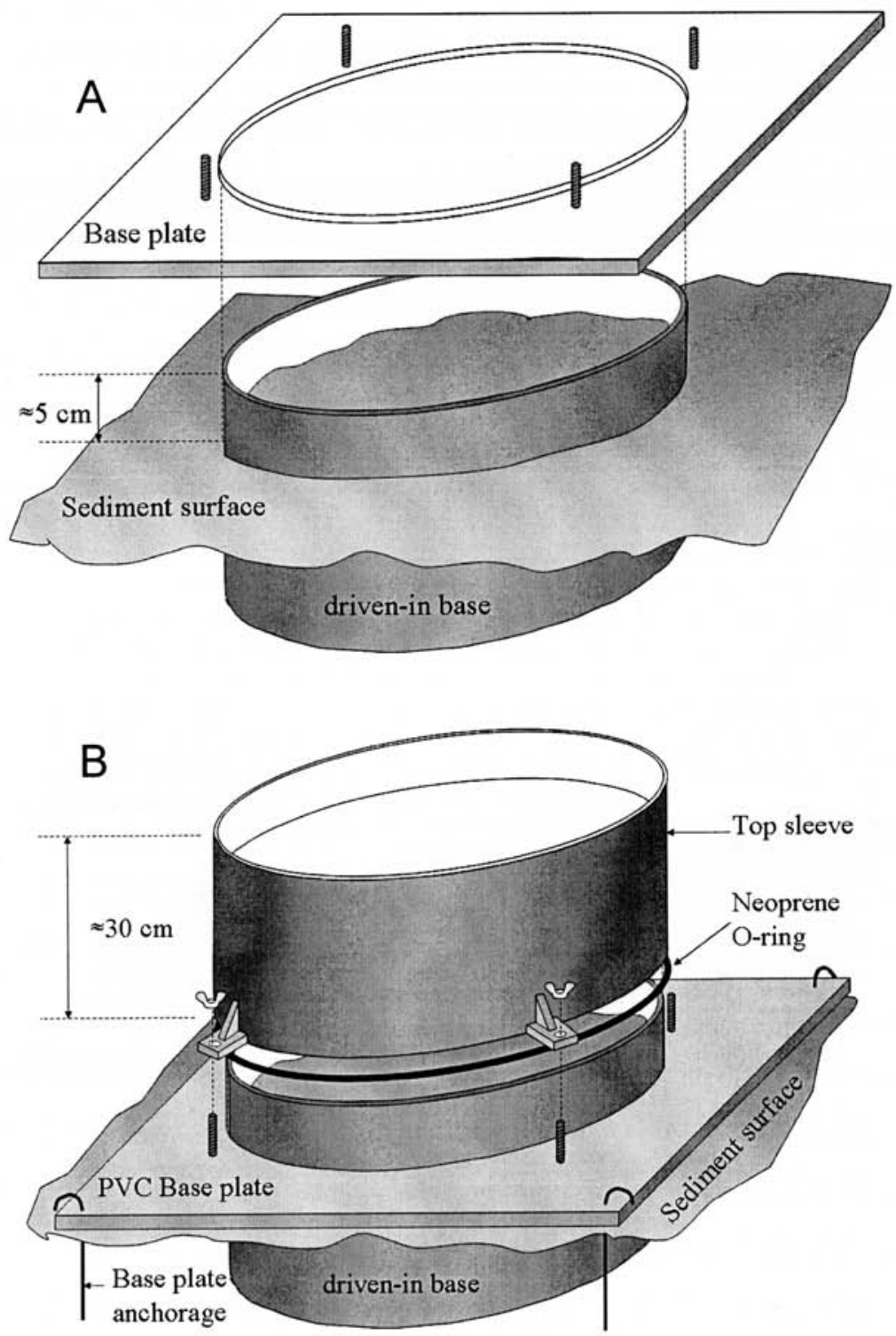

Fig. 1. Schematics of the field mesocosms: (A) permanent frame and (B) schematics of the installation during experiments

year. To best represent the main hydrological function, experiments were conducted on sediments of such ditches.

Three representative sites were chosen from the Cétrais hydrographic network: Coisbrac (COI) site, Mine (MIN) site and La Mare (MAR) site. Three mesocosms were extracted (upstream (AM), middle (MI) and downstream (AV)) at each site for laboratory assays and three permanent frames were installed nearby for in-situ studies. Annual average nitrate concentrations range between 7 and $8 \mathrm{mg} \mathrm{NO}-\mathrm{N} / \mathrm{L}$. The highest concentrations are usually measured during the first events of the fall and following fertilizer applications in the spring, reaching values as high as 15 to over 20 $\mathrm{mg} \mathrm{NO}$-N/L. Concentrations then tend to peak during flow peaks. Lowest concentrations (reaching nearly 0 $\mathrm{mg} \mathrm{NO}-\mathrm{N} / \mathrm{L}$ ) are usually measured at the end of the spring and the beginning of summer when flow rece- 
des. During winter, nitrate concentrations also reach low values during flow peaks, corresponding to an apparent dilution of water table nitrate by nearly nitratefree rain water. Ammonium concentrations are much lower, averaging $0.2 \mathrm{mg} \mathrm{NH}_{4}-\mathrm{N} / \mathrm{L}$ annually. Higher values (up to $0.5 \mathrm{mg} \mathrm{NH}_{4} \mathrm{~N} / \mathrm{L}$ ) can be measured in winter and exceptional peaks (up to $1.6 \mathrm{mg} \mathrm{NH}_{4} \mathrm{~N} / \mathrm{L}$ ), probably corresponding to sudden point source discharges, can be encountered. Dissolved phosphorus concentrations are low most of the time $\left(0.02 \mathrm{mg} \mathrm{PO}_{4}\right.$ $\mathrm{P} / \mathrm{L}$ ), rarely reaching $0.12 \mathrm{mg} \mathrm{PO}_{4}-\mathrm{P} / \mathrm{L}$ during the winter season.

For the in-situ experiments, nitrate uptake experiments were conducted using water overlying the sediment just before the experiment, as local water was actually isolated while adding the top sleeve on the permanent frame. In the laboratory, water added above the sediment came from the Cétrais watershed as it was pumped from one reach and brought back from the field the day before experiments started. In all cases, water in the mesocosms was recirculated using immersed aquarium pumps to best represent natural water movement above the sediment and to provide reaeration with the atmosphere.

A volume of $12 \mathrm{ml}$ of water was sampled at regular times during the experiments. To compensate for this uptake and for evaporation, an equivalent volume of distilled water was added in the laboratory experiments. No such additions were performed in the field. Water was then filtered at $0.45 \mu \mathrm{m}$ within 24 hours of sampling and kept frozen before analysis. Field samples were kept on ice before filtration. Water was then analyzed for nitrate and ammonium following standard methods (cadmium column reduction method for nitrate and nitroprusside method for ammonium) using a QuickChem8000 apparatus from Lachat instruments ${ }^{\circledR}$. Nitrate uptake rate values were calculated as the difference between the amount of nitrate (calculated as the product of the volume by nitrate concentration of water above the sediment) taken up between two consecutive water samples. This difference was then divided by the mesocosm section surface area and by the length of time between the two measurements, so as to express end results in $\mathrm{mg} \mathrm{N} . \mathrm{m}^{-2}$.day ${ }^{-1}$. Positive values indicated actual retention of nitrate in the mesocosm while negative values indicated nitrate release from the sediment to the water column.

Sediment characteristics were analyzed according to French Standard (NF X31-107, 2003). In these analyses, sediments were classified into five classes: clays: $(0-2 \mu \mathrm{m})$, fine silts $(2-20 \mu \mathrm{m})$, large silts $(20-50 \mu \mathrm{m})$, fine sands $(50-200 \mu \mathrm{m})$, and large sands (200$2,000 \mu \mathrm{m})$.

\section{Results}

\section{Sediment characteristics}

One of the hypotheses for the study was that a particular reach should have relatively stable sediment characteristics. This was the case for the Mare and Mine sites, which, respectively, were characterized by a silty (also containing gravel) type of sediment (Fig. 2), and, by fine silt on which a dense aquatic vegetation (Sium angustifolium L.; Waterparsnip) grew during a large part of the year. However, for the Coisbrac (COI) site, dramatic changes occurred in December 2002 when large amounts of immigrant sediment from upstream suddenly (within one week) covered the entire length $(250 \mathrm{~m})$ of the reach. This sediment most likely corresponded to bank erosion of a reach that was being restored several hundred meters upstream. This allochthonous sediment turned out to be fine sand (Fig. 2), which most likely changed the hydrodynamics and exchange rates at the sediment water interface.

Using three granulometric classes [clays $(0-2 \mu \mathrm{m})$, silts $(2-50 \mu \mathrm{m})$ and sands $(50-2000 \mu \mathrm{m})]$, it appears that the Coisbrac site contained the most sands $(88,8 \pm 2,6 \%$ on average), more so than the Mare $(60.1 \pm 5.5 \%)$ and Mine $(53.3 \pm 5.3 \%)$ sites. With regards to the fine granulometric range (clays and silts), La Mine sediments turned out to be finer $(46.8 \pm 7.5 \%)$ than La Mare ones $(39.9 \pm 6.3 \%)$, both being clearly higher than the Coisbrac sediments $(11.1 \pm 1.8 \%)$.

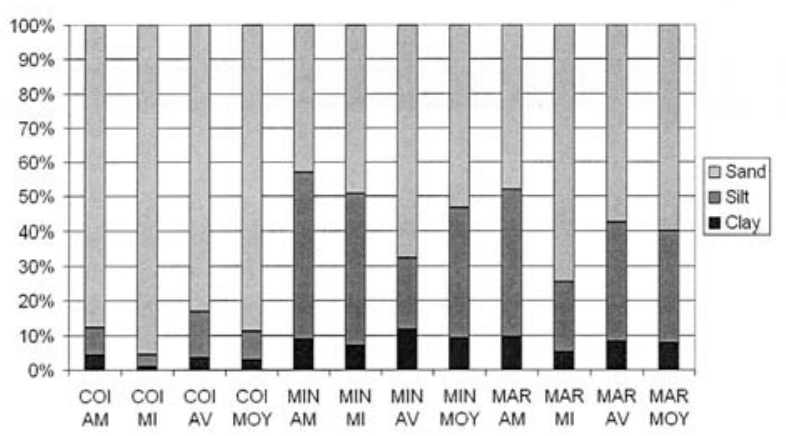

Fig. 2 . Sediment granulometry analysis for La Mine (MIN), La Mare (MAR) and Coisbrac (COI) samples. MIN MOY, MAR MOY and COI MOY correspond to the average value of the three replicates for each site.

\section{Laboratory experiments}

In the laboratory, nitrate concentrations decreased through time following an exponential decrease on all three sites. For Coisbrac mesocosms (COI AM, COI $\mathrm{MI}, \mathrm{COI} \mathrm{AV})$, concentrations fell from $7.5-8 \mathrm{mg} / \mathrm{L}$ $\mathrm{NO}_{3}-\mathrm{N}$ to $4.1-5 \mathrm{mg} / \mathrm{L} \mathrm{NO}_{3}-\mathrm{N}$ within 3 days (Fig. $3 \mathrm{~A}$ ), 

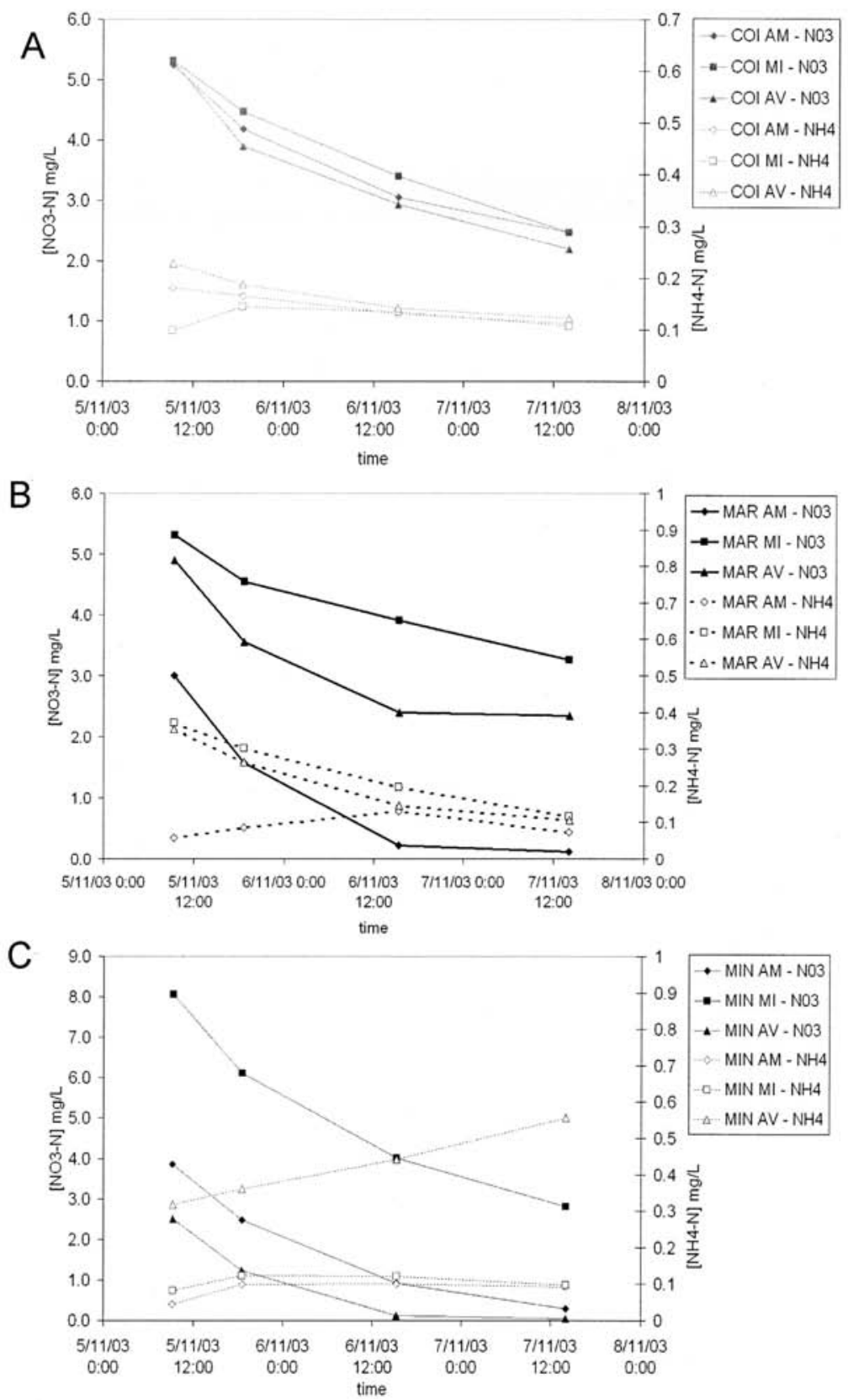

Fig. 3. Changes in nitrate and ammonium concentrations during laboratory experiments for (A) Coisbrac site (COI), (B) Mare site (MAR) and Mine site (MIN) mesocosms.

for water height above the sediment of $10 \mathrm{~cm}$. Similarly, for the Mare mesocosms (MAR MI and MAR $\mathrm{AV}$ ), nitrate concentrations (Fig. 3B) decreased from 5$6 \mathrm{mg} / \mathrm{L} \mathrm{NO}_{3}-\mathrm{N}$ to $3.5 \mathrm{mg} / \mathrm{L} \mathrm{NO}_{3}-\mathrm{N}$ within 3 days. For the same period of time, nitrate concentration in the upstream mesocosm from the Mare site (MAR AM) was divided by a factor of 30 , from $3.2 \mathrm{mg} \mathrm{NO}-\mathrm{N} / \mathrm{L}$ to $0.1 \mathrm{mg} \mathrm{NO} \mathrm{N}_{3} \mathrm{~N} / \mathrm{L}$. For La Mine mesocosms, (MIN AM and MIN AV), nitrate concentration was divided by a factor of 6 , to reach a $0.2-1.02 \mathrm{mg} / \mathrm{L} \mathrm{NO}_{3}-\mathrm{N}$ range during this 3-day experiment (Fig. 3C). Ammonium concentrations in the mesocosms remained generally 
low (0.1 to $0.3 \mathrm{mg} \mathrm{NH}_{4}$-N/L) throughout the experiment but never reached zero values (Fig. 3). Instead, for two mesocosms, ammonium concentration actually increased for several hours during the experiments before decreasing again. In other mesocosms, concentrations tended to decrease throughout the experiments.

From these results, nitrate uptake rates can be estimated from the slope of the nitrate concentration curves between two consecutive measurements. Fig. 3 clearly shows that the slopes diminish with decreasing concentrations. Uptake rates are thus obviously linked to nitrate concentration in the water column.

Many reports have suggested that nitrate uptake may be linearly correlated with nitrate concentration (reviewed by Birgand et al, in press) and decay coefficients have sometimes been derived from these observations. Concentrations $C(t)$ through time have thus been expressed as an exponential function of time such as:

$$
C(t)=C_{0} \times e^{(-K t)},
$$

where $\mathrm{C} 0$ is the initial concentration, $\mathrm{t}$ is residence time and $\mathrm{K}$ is the decay coefficient. Birgand et al. (in press) have recently pointed out that the decay coefficient is a function of the depth of the water column above the sediment and have proposed to use the mass transfer coefficient $\rho$ instead, where $K=\rho / D$, with $\mathrm{D}$ being the depth of the water column. Concentrations through time can thus be expressed as

$$
C(t)=C_{0} \times e^{\left(-\frac{\rho}{D} t\right) .}
$$

The values of the mass transfer coefficient are thus independent of concentration and indicate an "intrinsic ability" for sediment to retain nitrate. The mass transfer coefficient was evaluated as the slope of the best linear regression curve between the points of the function

$$
\ln \left(\frac{C(t)}{C_{0}}\right)=f\left(\frac{t}{D}\right)
$$

They are reported with the corresponding $\mathrm{R}^{2}$ in Table 1 , in addition to the initial nitrate uptake rates, the corresponding average nitrate concentration measured, and the range of temperatures encountered during experiment.

Results show, for instance, that initial nitrate uptake rates may be similar for the downstream laboratory mesocosm of the Coisbrac site (COI AV) and the upstream Mine (MIN AM) site (around $360 \mathrm{mg} \mathrm{N} \cdot \mathrm{m}^{-2} \cdot \mathrm{d}^{-1}$; Table 1). However, the nitrate concentrations at the time of measurement were much higher for the Coisbrac site than for the Mine site, 7.3 and $4.0 \mathrm{mg}$
$\mathrm{NO}_{3}-\mathrm{N} . \mathrm{L}^{-1}$, respectively (Fig. 3). It is therefore less than ideal to compare these results directly. Mass transfer coefficients instead provide a better evaluation of uptake potential.

In this particular set of experiments, sediment from the Mine site seem to have higher potential for removing nitrate as the mass transfer coefficients were generally calculated to be higher than for the other two sites. This conclusion could not be reached on the sole basis of the nitrate uptake rates.

\section{Results from in-situ experiments}

In situ experiments were designed to confirm laboratory results and to investigate nitrate uptake variations throughout the year. Results obtained from the in-situ mesocosms turned out to be very different than the ones obtained in the laboratory. A general pattern of decreasing nitrate concentrations was generally seen. However, a temporary rise in nitrate concentrations could be observed for a number of mesocosms (Fig. 4, series I). The exponential decay approach could not be applied and the mass transfer coefficients were thus not calculated. Initial nitrate uptake rates were calculated however, and are reported in Table 1. The equivalent of the mass transfer coefficient was calculated $\left(\rho^{\prime}\right)$ for the initial uptake rate by dividing the rates by the average concentration in the mean time. They are reported in the table for comparison purposes.

Nitrate concentrations outside the mesocosms were measured at the same time as the inside concentrations, to check for actual water tightness of the apparatus and thus possible contamination between the two waters. Results suggest that in the vast majority of time, there was no obvious contamination between the two. This can be easily verified for the mesocosm on the Mare site (Figure 4B), while such a conclusion could be difficult to reach on the example of the Coisbrac site (Figure 4A).

Ammonium concentrations in the field tended to fluctuate more than in the laboratory and increase for a number of mesocosms. This seemed particularly true for the finer sediments (Coisbrac site) than for the more gravelly ones (Mare site).

\section{Discussion}

The need for a simple method for evaluating instream nitrate uptake has been reported on several occasions in the literature (e.g. Laursen \& Seitzinger 2005, Birgand et al. in press). Historically, many authors have reported studies performed on water overlying small sediment cores in the laboratory, usually of 

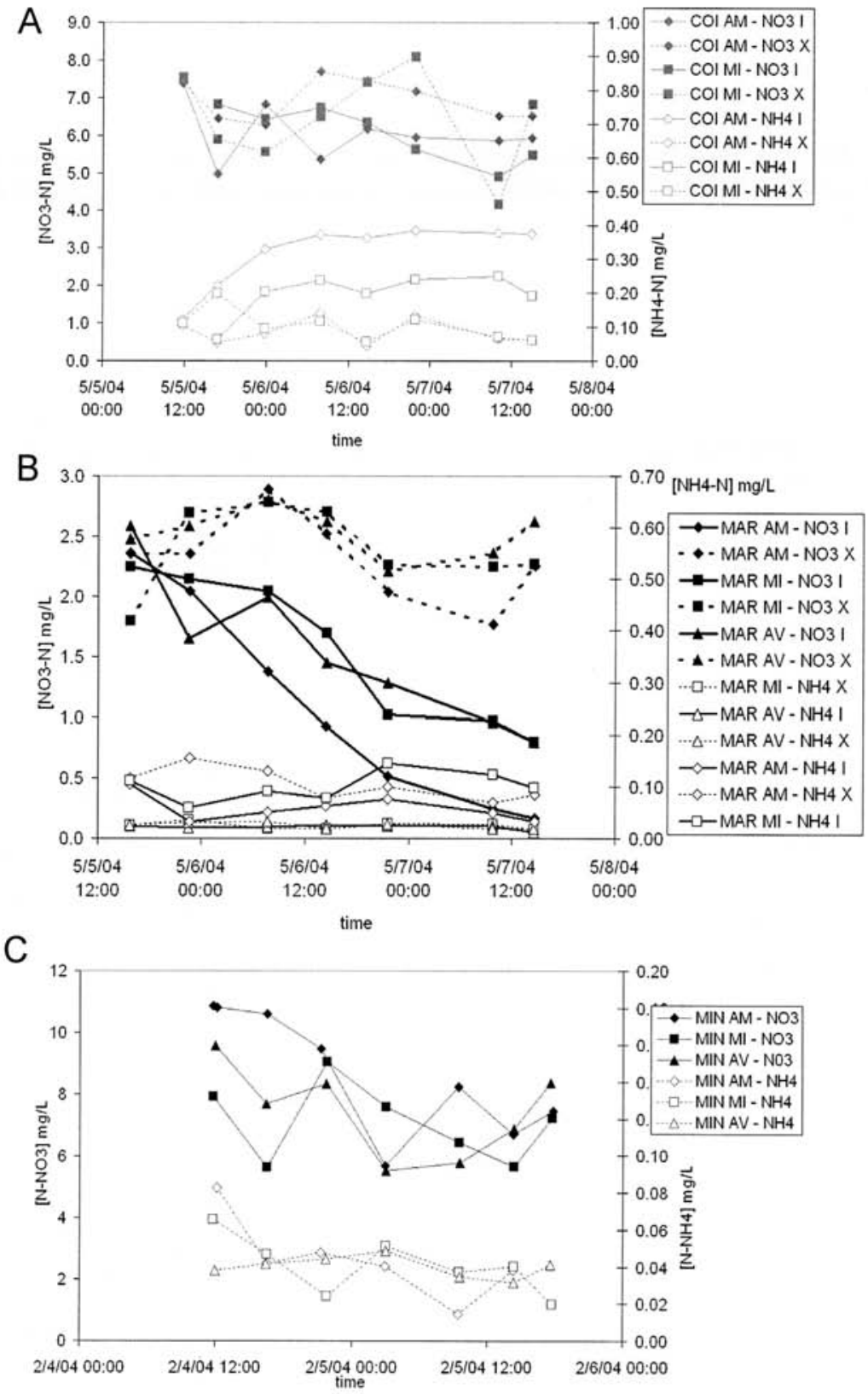

Fig. 4. Changes in of nitrate and ammonium concentrations during field experiments for (A) Coisbrac site (COI), (B) Mare site (MAR) and (C) Mine site (MIN) mesocosms

the size of several centimeters $(5$ to $10 \mathrm{~cm}$ ) in diameter (e.g. Sain et al. 1977, Hill 1981, 1983, Christensen \& Sørensen 1988, Pind et al. 1997, García-Ruiz et al. 1998, reviewed by Birgand et al. in press). Our hypothesis is that this method is appealing because of its simplicity, although the spatial variability covered by $5 \mathrm{~cm}$ or so in diameter sediment cores was thought to be insufficient. Choosing mesocosms $30 \mathrm{~cm}$ in diameter was an effort to incorporate more of the spatial variability. 
Table 1. Replicate values for temperature, initial nitrate uptake rates, the corresponding nitrate concentration, nitrate uptake potential (_ ) and $\mathrm{R}_{-}$ associated, from the three studied sites

\begin{tabular}{|c|c|c|c|c|c|c|c|c|}
\hline \multirow[t]{3}{*}{ sample } & \multicolumn{4}{|c|}{ Laboratory experiments } & \multicolumn{4}{|c|}{ In-situ Experiments } \\
\hline & $\begin{array}{l}\text { Water } \\
\mathrm{T}^{\circ} \mathrm{C}\end{array}$ & $\begin{array}{l}\text { Initial nitrate } \\
\text { uptake }\end{array}$ & [NO3-N] & $\rho$ & $\begin{array}{l}\text { Water } \\
\mathrm{T}^{\circ} \mathrm{C}\end{array}$ & $\begin{array}{c}\text { Initial } \\
\text { nitrate } \\
\text { uptake }\end{array}$ & [NO3-N] & $\rho^{\prime}$ \\
\hline & ${ }^{\circ} \mathrm{C}$ & $m g N \cdot m^{-2} \cdot d^{-1}$ & $m g N \cdot L^{-1}$ & $\begin{array}{l}m \cdot d^{-1} \\
\left(R^{2}\right)\end{array}$ & ${ }^{\circ} \mathrm{C}$ & $m g N \cdot m^{-2} \cdot d^{-1}$ & $m g N \cdot L^{-1}$ & $m \cdot d^{-1}$ \\
\hline COI AM & $16-20$ & 275 & 6.7 & $\begin{array}{l}0.024 \\
(0.93)\end{array}$ & $13-17$ & 1445 & 6.2 & 0.233 \\
\hline $\mathrm{COI} \mathrm{MI}$ & $16-20$ & 217 & 7.4 & $\begin{array}{l}0.021 \\
(0.99)\end{array}$ & $13-17$ & 268 & 6.6 & 0.040 \\
\hline COI AV & $16-20$ & 361 & 6.6 & $\begin{array}{l}0.027 \\
(0.90)\end{array}$ & - & - & - & - \\
\hline MIN AM & $16-20$ & 361 & 3.3 & $\begin{array}{l}0.107 \\
(0.99)\end{array}$ & $13-17$ & 152 & 10.7 & 0.014 \\
\hline MIN MI & $16-20$ & 506 & 7.5 & $\begin{array}{l}0.047 \\
(0.97)\end{array}$ & $13-17$ & 1519 & 6.8 & 0.224 \\
\hline MIN AV & $16-20$ & 333 & 1.9 & $\begin{array}{l}0.155 \\
(0.91)\end{array}$ & $13-17$ & 1337 & 8.6 & 0.155 \\
\hline MAR AM & $16-20$ & 370 & 2.3 & $\begin{array}{l}0.164 \\
(0.95)\end{array}$ & $13-17$ & 170 & 2.2 & 0.077 \\
\hline MAR MI & $16-20$ & 199 & 4.9 & $\begin{array}{l}0.023 \\
(0.96)\end{array}$ & $13-17$ & 40 & 2.2 & 0.018 \\
\hline MAR AV & $16-20$ & 349 & 5.0 & $\begin{array}{l}0.033 \\
(0.73)\end{array}$ & $13-17$ & 588 & 2.1 & 0.277 \\
\hline
\end{tabular}

While laboratory incubations are easier to perform, environmental conditions can be somewhat remote from those encountered in the field. For that purpose, several authors have proposed to measure nitrate uptake using benthic chambers in the field (e.g. Chestérikoff et al. 1992, Torre et al. 1992, Duff et al. 1996). We decided not to choose this method because it prevents atmospheric reaeration due to the complete isolation of the volume of water from the atmosphere. Indeed, sediment oxygen consumption may significantly reduce oxygen concentration in the water column, and thus change biogeochemical processes at the sediment-water interface. Instead, in-situ mesocosms similarly isolate a volume of water above the sediment but also provide reaeration from the atmosphere, as they provide an air-water interface. Using both laboratory and insitu mesocosm incubations has been proposed earlier in low land, forested, and slow moving streams overlying highly organic sediment (Appelboom 2004). To our knowledge, there is no report of such use and comparison in faster moving streams $\left(30-50 \mathrm{~cm} . \mathrm{s}^{-1}\right)$ overlying mineral sediments. Results from the laboratory incubations showed an exponential decrease of nitrate concentrations through time in the mesocosm. This observation corresponds to many others reported in the li- terature (e.g. Van Kessel 1977, Hoare 1979, Hill 1981, Cooper \& Cooke 1984, Kelly et al. 1987, Birgand 2000, Appelboom 2004). Results from the calculation of the mass transfer coefficient show that the exponential decay hypothesis is acceptable in our case. Indeed, values of $\mathrm{R}^{2}$ for the linear regressions performed to calculate $\rho$ are above 0.90 for all but one, and for the majority above 0.95 . For MAR AV, the value only reached 0.73 as nitrate concentration shows nearly no decrease in the last 24 hours of incubation (Table 1). These results in the laboratory seem to confirm the general hypothesis that nitrate uptake in streams is linearly correlated to nitrate concentration in the water column. Although the actual mechanisms for nitrate dissipation have not been measured in our case, the literature on the subject suggests that it probably corresponds to denitrification in sediment, despite the presence of oxygen in the water column (Birgand et al. in press). The actual transport of nitrate near the attached denitrifying microorganisms involves, at least near the denitrifying sites, diffusion processes. As a result, it is not unexpected to find that nitrate dissipation near those sites is proportional in part to the nitrate concentration gradient, thus the overall apparent dissipation. 
The relative stability of ammonium concentrations in laboratory mesocosms suggests that atmospheric reaeration was probably effective in most of the mesocosms. The downstream mesocosm from the Mine site shows a constant accumulation of ammonium in the water column, however, suggesting that reaeration was probably ineffective in that particular case. This was probably the result of the aquarium pump malfunctioning, as was unfortunately observed to be happening at times. Figure 4 clearly shows that laboratory results did not translate well to the field. Although the overall tendency was towards a decrease in the nitrate concentrations, unexpected temporary concentration increases were regularly observed. Double-checking did not reveal possible analytical errors in the laboratory. Observed variations were thus very likely to have actually occurred. Possible contamination from outside water was also evaluated but in most cases, it seems that the neoprene O-ring provided good isolation between mesocosm and stream waters. Actual concentration fluctuations most likely occurred due to water level fluctuations measured within the mesocosm. Indeed, within the 48-hour in-situ incubations, water level fluctuated over $1 \mathrm{~cm}$, reaching lowest values at midday and highest values at the end of the night (data not shown). These variations are actually rather well known in hydrology as they are commonly recorded in summer times at gauging stations. These fluctuations were actually measured several times during the year and may actually be more present than usually perceived. Periods for in-situ measurements were always chosen in the receding part of the hydrograph so that the general tendency would be towards a decrease of water level in the mesocosms. A small rise in the water level outside the mesocosm most likely induced a hydraulic gradient in the hyporheic zone below the mesocosm, which tended to force some of the hyporheic water into the mesocosm water column. It is very likely that this water contained significant ammonium concentrations. The temporary rise of nitrate concentration in the mesocosm may have been caused by the nitrification of the hyporheic ammonium at the sediment water interface. However, this explanation would lead towards a synchronization of the nitrate concentration rise and fall between the mesocosms as the experiments were conducted at the same time. Our results do not show such obvious synchronization and other factors should be taken into consideration. One possible factor could be the sudden change in the hydrodynamics due to installation of the mesocosm in the field. Indeed, despite recirculation provided by aquarium pumps, the actual path and velocity of water above the sediment probably changed quite drastically. It is possible that there was a transition period for new biogeochemical equilibria to be reached. Such concentration fluctuations were not observed by Appelboom (2004) in lowland and forested streams in the lower coastal plain of North Carolina. Concentration profiles largely resembled those obtained in the laboratory. The organic nature of the sediment may have reduced hydraulic conductivities in the hyporheic zone, reducing at the same time the possible influence of water level fluctuations outside the mesocosms. The use of in-situ mesocosm in relatively fast moving streams $\left(30-50 \mathrm{~cm} \cdot \mathrm{s}^{-1}\right)$ overlying mineral sediment is probably a more delicate operation than a priori thought. The use of benthic chambers for several hours only to preserve dissolved oxygen concentration in the water column, could have been an interesting alternative as outside water level fluctuations would not have led to a hydraulic flux inside the chamber. However, the use of chambers in the relatively shallow streams was difficult in our case and is probably difficult in upstream agricultural streams in general.

Following the above discussion, the question that arises is: are mesocosms suitable for measuring instream nitrate uptake, and if so, which method should one choose? Laboratory results are comforting because they correspond to expectations. Nitrate uptake potential can also be easily calculated, which is in our opinion a major advantage. However, laboratory mesocosms artificially isolate sediments from the surrounding hyporheic zone and that, in light of the in-situ results, might be a major bias. Indeed, in-situ mesocosms demonstrate that small and common water level fluctuations in streams can generate important hyporheic exchange, which may have a dramatic impact on the actual direction of nutrient fluxes at the sediment water interface. The concept of nitrate uptake by the sediment makes the basic assumption that there is a net flux of nitrate from the water column into the sediment. Laboratory results show that this assumption is relatively well verified when there is no net gain or loss of water from or into the sediment. In-situ results show that this situation is probably rare in the field, because of common fluctuations of stream and groundwater levels. However, it is unclear whether in-situ mesocosms provided a closer representation of the direction and magnitude of exchanges at the sediment-water interface. Indeed, as seen earlier, a rise in the stream water level outside the mesocosms probably induced a partly artificial flux of the hyporheic zone into the water column, as the hydraulic head inside the mesocosms could not be compensated due to the good isolation provided by the neoprene O-ring. It is our opinion that for this reason, there was an important bias in the in-situ experi- 
ments, which prevented a meaningful use of these results. One way to improve the experiment would have been to link the inside and outside mesocosm water heads by a siphon, using a simple air bubble to isolate water and record the actual direction of flow. Using a similar approach in future experiments in the field should remove the major bias unveiled in this paper.

In light of the discussion above, it seems tempting to recommend the use of laboratory mesocosms over the in-situ ones, for the results can be easily interpreted and quantified. However, our comparative study shows that for relatively fast moving stream above mineral sediments, hyporheic exchanges may be extremely important for the magnitude and direction of nitrate fluxes at the sediment-water interface. Laboratory mesocosms are ill-designed to take these processes into account. Our in-situ mesocosms study did not foresee the possible bias associated with artificial hyporheic exchange due to head difference between the inside and outside of the mesocosms. We would not recommend the same use for future studies. However, a simple device to equilibrate inside and outside water heads, would probably correct for this major bias. Doing so would render the in-situ mesocosms to be particularly interesting and is probably a promising approach to studying in-stream nitrate uptake and processes at the sediment-water interface. Extrapolating our results to evaluate the magnitude of in-stream nitrate uptake in the nitrogen budget of our studied watershed is a difficult and risky task. The difficulty lies in part in the relevance of using the mass transfer coefficient approach for modeling in-stream nitrate uptake, which could not be confirmed in our study here, and to apply it to the different sediment characteristics of the watershed. This task is also risky because extrapolating results from $30 \mathrm{~cm}$ diameter mesocosms to the surface covered by a stream reach sediment is not straightforward as shown by Birgand et al. (in press).

\section{Acknowledgements}

This study was funded by Cemagref (center of Rennes, Livestock and municipal wastes management unit). The authors also want to thank P. Saint-Cast, M. Loubat, E. Le Saos, and P. Serrand for their technical assistance in the field and in the laboratory.

\section{References}

Alexander R.B., Smith R.A. \& Schwarz G.E. 2000. - Effect of stream channel size on the delivery of nitrogen to the Gulf of Mexico. Nature, 403, 758-761.

Appelboom T.W. 2004. - Effects of in-stream processes on the fate of nitrogen and phosphorus in drainage canals of forested watersheds. Doctoral Thesis. North Carolina State University., 314 p.

Baden S.P., Loo L.O., Pihl L. \& Rosenberg R. 1990. - Effects of eutrophication on benthic communities including fish: Swedish west coast. Ambio, 19, 113-122.
Birgand F. 2000. - Quantification and modeling of in-stream processes in agricultural canals of the lower coastal plain. Doctoral dissertation -North Carolina State University, Raleigh, NC, USA, 469 p.

Birgand, F., Skaggs R.W., Chescheir G.M. \& Gilliam J.W. in press Nitrogen removal in streams of agricultural catchments - a literature review. Critical Reviews in Environmental Science and Technology.

Burkholder, J.M., Glasgow H.B., Noga E.J. \& Hobbs C. W. 1993.The role of a new toxic dinoflagellate in finfish and Shellfish kills in the Neuse and Pamlico estuaries. Report No. 93-08, Albemarle Pamlico Estuarine Study. Raleigh, North Carolina Department of Environment, Health and Natural Resources and U.S. Environmental Protection Agency - National Estuary Program, 58 pp. (3rd printing).

Burchell, M.R. 2003. - Practices to Reduce Nitrate-Nitrogen Losses from Drained Agricultural Lands. Doctoral dissertation. North Carolina State University, Raleigh, NC, USA. 333 p.

EEC (1991) - Council Directive 91/676/EEC, 12 December 1991, concerning the protection of waters against pollution caused by nitrates from agricultural sources

Christensen P.B. \& Sørensen J. 1988. - Denitrification in sediment of lowland streams: regional and seasonal variation in Gelbæk and Rabis Bæk, Denmark. FEMS Microbiol. Ecol., 53, 335-344.

Clean Waters Act Section 319. 1987. - A bill to amend the Federal Water Pollution Control Act to provide for the renewal of the quality of the Nation's waters, and for other purposes. Public Law: 100-4 (02/04/87).

Cooper A.B. \& Cooke J.G. 1984. - Nitrate loss and transformation in 2 vegetated headwater streams. N.Z.J.Mar. Freshwater Res., 18, 441-450.

Delajon D. 1998. - Bassin de Nozay : approche hydrologique quantitative, Mémoire de DEA, Univ. Angers, laboratoire des sciences de l'environnement et de l'aménagement / Cemagref DEAN.

Duff J.H., Pringle C.M. \& Triska F.J. 1996. - Nitrate reduction in sediments of lowland tropical streams draining swamp forest in Costa Rica; an ecosystem perspective. Biogeochem., 33, 179-196.

García-Ruiz R., Pattinson S.N. \& Whitton B.A. 1998. - Denitrification in sediments of the freshwater tidal Yorkshire Ouse. Sci. Tot. Environ., 210, 321-327.

Hallegraeff G.M. 1993. - A review of harmful algal blooms and their apparent global increase. Phycologia, 32(2), 79-99.

Hill A.R. 1981. - Nitrate-nitrogen flux and utilization in a stream ecosystem during low summer flows. Can. Geograph., 25, 225-239.

Hill A.R. 1983. - Nitrate-nitrogen mass balances for two Ontario rivers. Pages 457-477 In Dynamics of lotic ecosystems, Ann Arbor Sciences Publ., Michigan, Thomas D. Fontaine, III, Steven M. Bartell eds.

Hoare R.A. 1979. - Nitrate removal from streams draining experimental catchments. Prog. Wat. Tech., 6, 303-314.

Howarth R.W., Billen G., Swaney D., Townsend A., Jaworski N., Lajtha K., J.A.Downing, Elmgren R., Caraco N., Jordan T., Berendse F., Freney J., Kudeyarov V., Murdoch P. \& Zhao-Liang Z. 1996. - Regional nitrogen budgets and riverine N \& P fluxes for the drainages to the North Atlantic ocean: natural and human influences. Biogeochem., 35, 75-139.

Ingersoll T.L. \& Baker L.A. 1998. - Nitrate removal in wetland microcosms. Wat. Res., 32(3), 677-684.

Justić D., Rabalais N.N., Turner R.E. \& Dortch Q. 1995. - Changes in nutrient structure of river-dominated coastal waters: stoichiometric nutrient balance and its consequences. Estuar. Coast. Shelf Sci., 40, 339-356.

Kelly C.A., Rudd J.W.M., Hesslein R.H., Schindler D.W., Dillon P.J. \& Driscoll, S.A.Gherini and R.E.Hecky C.T. 1987. - Prediction of biological acid neutralization in acid-sensitive lakes. Biogeochem., 3, 129-140. 
Larsson U., Elmgren R. \& Wulff F. 1985. - Eutrophication and the Baltic sea: causes and consequences. Ambio, 14(1), 9-14.

Laursen A. \& Seitzinger S. 2005. - Limitations to measuring riverine denitrification at the whole reach scale: effects of channel geometry, wind velocity, sampling interval, and temperature inputs of N2-enriched groundwater. Hydrobiologia, 545, 225-236.

NF X31 (2003), Norme Française NF X31-107 Détermination de la distribution granulométrique des particules du sol, septembre 2003.

Pind A., Risgaard-Petersen N. \& Revsbech N.P. 1997. - Denitrification and microphytobenthic NO3- consumption in a Danish lowland stream: Diurnal and seasonal variation. Aquat. Microbiol. Ecol., 12(3), 275-284.

Rosenberg R. 1985. - Eutrophication - The future marine coastal nuisance. Mar. Pollut. Bull., 16, 227-231.

Rückauf U., Augustin J., Russowb R. \& MerbachW. 2004. - Nitrate removal from drained and reflooded fen soils affected by soil $\mathrm{N}$ transformation processes and plant uptake. Soil Biol. Biochem. 36(1), 77-90.

Sain P., Robinson J.B., Stammers W.N., Kausshik N.K. \& Whiteley H.R. 1977. - A laboratory study on the role of stream sediment in nitrogen loss from water. J. Environ. Qual., 6(3), 274-278.
Stief P., Schramm A., Altmann D., de Beer D. 2004. - Temporal variation of nitrification rates in experimental freshwater sediments enriched with ammonia or nitrite. FEMS Microbiol. Ecol. 46 (1), 63-71

Torre M., Rebillard J.P., Ayphassorho H., Labroue L. \& Helmer C. 1992. - In situ assessment of denitrification in running waters: example of the Charente river (Etude expérimentale de dénitrification in situ en eaux courantes: application à la rivière Charente). Ann. Limnol., 28(3), 263-271.

Valiela I., Foreman K., Lamontagne M., Hersh D., Costa J. Peckol P., DeMeo-Andreson B., D'Avanzo C., Babione M., Sham C.H., Brawley J. \& Lajtha K.1992. - Couplings of watersheds and coastal waters - sources and consequences of nutrient enrichment in Waquoit Bay, Massachusetts. Estuaries, 15(4), 443-457.

Van Kessel J.F. 1977. - Removal of nitrate from effluent following discharge on surface water. Wat. Res., 11, 533-537.

Yang L., Chang H.T., Huang M.N.L. 2001. - Nutrient removal in gravel- and soil-based wetland microcosms with and without vegetation. Ecol. Eng. 18 (1), 91-105. 